\title{
Improving the efficiency of operation of electrified reclamation pumping stations
}

\author{
Fyarid Abdrazakov ${ }^{1, *}$, Denis Logashov ${ }^{1}$, and Andrey Rukavishnikov ${ }^{2}$ \\ ${ }^{1}$ Saratov GAU, 410012, 1, Teatralnaya sq. str., Saratov, Russian Federation \\ 2 Saratov GAU College of Finance and Technology, 410012, 97, Michurina str., Saratov, \\ Russian Federation
}

\begin{abstract}
This article discusses the topical issue of improving the efficiency of operation of electrified reclamation pumping stations. In the introduction, the state of the reclamation complex of the Saratov region is considered, the present state of the reclamation systems of the Saratov region is given, and the main functions of the modern irrigation system are also considered. The materials and methods section includes the principle of operation of pumping stations, as well as the processes occurring in them. Theoretical analysis of fluid motion is an integral part of the study of pumping equipment. The existing schemes of arrangement of centrifugal pumps are presented. Negative cavitation phenomena are listed. The results of the study include structural changes in the position of the suction bell and a positive economic effect during its further operation.
\end{abstract}

\section{Introduction}

One of the regions with the most developed irrigation system in the Volga region is the Saratov region, while agriculture in the Saratov region is conducted in arid conditions, and it is this factor that primarily determines the volume and stability of crop and livestock production.

Saratov region has a large irrigated area. Since 1966, operational measures for reclamation construction have been taken in the region. The most intensive period is considered to be from 1970 to 1975 , when an average of 50 thousand hectares were introduced per year. At the end of 1987, the irrigated area was 481.4 thousand irrigated hectares. With the passage of time and the gradual deterioration of the elements of irrigation systems, the irrigated area gradually decreased, starting from 1991 to 2004.

To date, the irrigated area is 257.3 thousand hectares. With the launch of the expanded reclamation program in Russia, it is planned to increase the irrigated area. It is important to note that the commissioning of new irrigation systems and canal branches will not have a significant result without the restoration of existing irrigation systems, including all the primary elements of the system (canals, pumping equipment, etc.). The state of the reclamation complex of the Saratov region is presented in Table 2.

\footnotetext{
* Corresponding author: abdrazakov.fk@mail.ru
} 
Table 1. The state of the reclamation complex of the Saratov region, 2020.

\begin{tabular}{|c|l|c|c|}
\hline \multirow{2}{*}{ № } & \multicolumn{1}{|c|}{ Designation } & Total number & $\begin{array}{c}\text { Including on } \\
\text { the state. } \\
\text { Institutions }\end{array}$ \\
\hline \multirow{2}{*}{1} & $\begin{array}{l}\text { Availability of irrigated lands, thousand. ha } \\
\text { regular irrigation } \\
\text { estuary irrigation }\end{array}$ & 257,3 & 214,0 \\
\hline \multirow{2}{*}{2} & Length of trunk and inter-farm canals, km & 25,1 & 1002 \\
& including lined & 1472 & 617 \\
& Length of pipelines, km & 707 & 4226 \\
\hline \multirow{2}{*}{3} & Structures on the irrigation network, including & 5210 & 1257 \\
& trunk and inter-farm canals & 1401 & \\
& Pumping stations & 1033 & 358 \\
\multirow{2}{*}{4} & Total including stationary, mobile types: & 360 & 338 \\
& SIL, & - & - \\
& SPS & 653 & 338 \\
& floating type "Rosa", PH & 20 & 41 \\
\hline \multirow{2}{*}{5} & Reservoirs, unit & & 394 \\
\hline \multirow{2}{*}{6} & Useful volume at the NPG, million $\mathrm{m}^{3}$ & 3344 & 2646 \\
& Sprinkler machines, units. & 2332 & 6247 \\
\hline 7 & including "Frigate" & 6795 & \\
\hline
\end{tabular}

The largest irrigation systems of the Saratov region today are the Saratov irrigation Canal, the Volga, Engels and Komsomol systems. Considering the fact that a significant part of the systems were introduced in the 70-80 years of the last century, the average wear value is $55-60 \%$. In comparison with the systems put into operation at the beginning of 1985, the irrigation systems Pugachevskaya, Hiradskaya, Komsomolskaya also have an average wear value of more than $20 \%$. We present the data for each system in Table 2 .

Over time, the reduction of irrigated areas becomes the norm, which is unacceptable from the point of view of reclamation production and agriculture in general. Since one of the problems of the described processes is the technical condition of hydraulic structures, namely irrigation canals, it is necessary to consider all possible ways to restore irrigation canals to the required characteristics and, accordingly, fulfill the necessary irrigation norms of agricultural crops.

It is also worth noting that the third part of the irrigation canals is not lined, which leads to increased filtration through the bottom and slopes of the channel, an increase in groundwater and, as a consequence, flooding of nearby territories and farms.

As we can see, each irrigated system has a certain amount of irrigated areas, the reduction or increase of which will directly affect the state of the agricultural sector in Russia.

The water intake structure, irrigation network and its branches, pipelines, pumping equipment, temporary sprinklers, roads and communication facilities, etc. are the structural elements of the system, the stable functioning of which ensures the efficient operation of the system. Let's imagine the functionality of the irrigation system for each element in Figure 1. 
Table 2. The state of irrigation systems in the Saratov region.

\begin{tabular}{|c|l|c|c|c|}
\hline $\mathbf{N o}$ & $\begin{array}{l}\text { Name of the reclamation } \\
\text { system }\end{array}$ & $\begin{array}{c}\text { Final } \\
\text { commissioning }\end{array}$ & $\begin{array}{c}\text { Degree of } \\
\text { wear, \% }\end{array}$ & $\begin{array}{c}\text { Area, } \\
\text { thousand } \\
\text { hectares. }\end{array}$ \\
\hline 1 & Dukhovnitskaya & 1976 & 60,5 & 4,8 \\
\hline 2 & Privetskaya & 1991 & 30,3 & 11,5 \\
\hline 3 & Balakovskaya & 1985 & 35,6 & 15,1 \\
\hline 4 & Malaya Balakovskaya & 1970 & 67,3 & 3,8 \\
\hline 5 & Komsomolskaya & 1985 & 31,7 & 18,1 \\
\hline 6 & Saratov canal & $1971-1990$ & 70,8 & 47,5 \\
\hline 7 & $\begin{array}{l}\text { Privolshkaya (the northern } \\
\text { massif) }\end{array}$ & 1987 & 38,9 & 40,7 \\
\hline 8 & $\begin{array}{l}\text { Privolshkaya (Southern } \\
\text { massif) }\end{array}$ & 1986 & 32,1 & 12,5 \\
\hline 10 & Pugachevskaya & 1988 & 24,3 & 2,8 \\
\hline 11 & Engelskaya & 1976 & 51,8 & 24,6 \\
\hline 12 & State irrigation plots & $1975-1990$ & 47,6 & 31,6 \\
\hline 12 & $\begin{array}{l}\text { Economic irrigation systems } \\
\text { and plots }\end{array}$ & $1996-1991$ & 58,1 & 44,3 \\
\hline & \multicolumn{2}{|c|}{ Итого } & 49,5 & 257,3 \\
\hline
\end{tabular}

Each element shown in Figure 1 and their corresponding functions are integral parts of each other, depending on the chosen irrigation system model. Let's look at each function in detail.

The water intake function is responsible for the intake of water from the irrigation source and its further transportation by gravity, using the terrain features or additional structures for lifting water.

Water treatment function. This function is responsible for bringing the water composition to the required quality (clarification, removal of impurities, biological purification by filtration, maintain the required level of mineralization). Also, the thermal regime of water is an important aspect. Water treatment is an important stage, since the quality of the work carried out depends on the water.

The transport function involves the movement of water resources to irrigated areas through irrigation canals. Water transportation is the most energy-consuming and complex process. To deliver the maximum amount of irrigation water, it is necessary to properly design the branches of the network, as well as prepare irrigation canals in such a way as to prevent significant water losses for filtration and destruction of canals during operation.

Irrigation function includes rational water use of irrigation water after its delivery to irrigated areas.

The water circulation function is quite important and requires additional attention. This function is intended for the removal of excessively supplied and unrealized water and the removal of part of the water from groundwater to maintain favorable biological conditions on reclaimed lands.

At this point in time, the discharge of excess resources in the form of irrigation water is a waste, since it is necessary to spend certain human and material resources on the delivery and intake of water. The issue of filling canals in the required volume is an open issue requiring operational solutions in a period of limited resources. 
- Water intake structure
- Dams
- Technical means and structures of machine water lifting

Technical means and structures of machine water lifting

\section{- Ponds settling tanks clarifiers \\ - Water treatment stations \\ - Facilities for regulating the thermal regime of water \\ - Facilities for regulating water mineralization}

Function \#1.

Water intake function
Function \#2.

Water treatment function

Function \#3.

Transport function

Function \# 4.

Irrigation

Function \#5.

Water circulation

function

Fig. 1. Functions of the irrigation system.

It is also important to note that if it is possible to regulate the level of filling of irrigation canals with water, it becomes possible to reduce water losses for filtration and the overall load on the canals. However, with this approach, it is necessary to ensure the smooth operation of pumping equipment.

\section{Methods}

As the main materials and well-known methods, we will rely on the research of Tarasyants S.A. and Pashkov P.V. These scientists are engaged in similar research and have enough material for the theoretical and practical basis of our research. General formulas for the discipline of hydraulics and mathematical analysis are given.

The movement of liquid in a narrowing pipeline, in the form of a Venturi tube, in a narrow section, the velocity, as a rule, reaches maximum values, and the pressure in turn decreases.

This process is best represented in Figure 2. where the pressure value in a narrow section 2-2 in accordance with the D. Bernoulli equation is as follows: 


$$
P_{2}=P_{1}-\frac{\left(V_{2}^{2}-V_{1}^{2}\right)}{2 g},
$$

where $\mathrm{P}$ - liquid density; $\mathrm{V}$ - flow rate; $\mathrm{g}$ - acceleration of free fall.

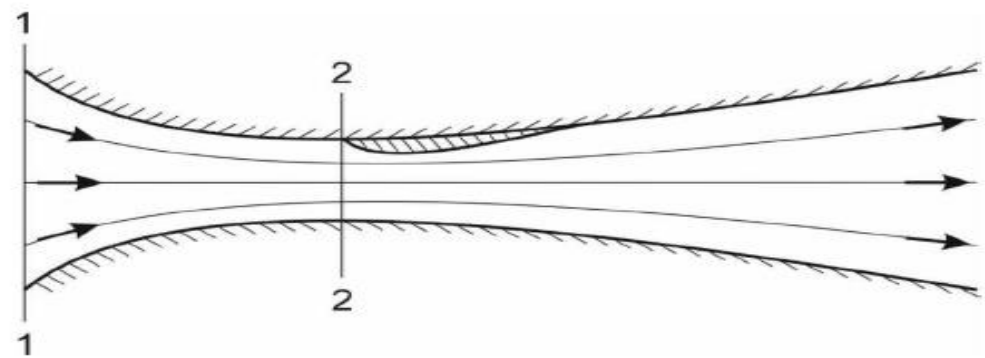

Fig. 2. Flow diagram of fluid in a narrowing vessel.

Based on these schemes, the pressure decreases, it is also noted that in some cases the pressure may become negative. Lowering the pressure may cause the liquid to boil. The process by which the liquid boils is called vaporization. It follows that when the liquid boils and steam forms in the pipeline, cavities filled with steam are formed, called cavities. The boiling of a liquid at low pressure, the process of formation of which occurred as a result of an increase in the flow rate and filling the liquid cavity with steam, is called cavitation.

As is known, with a back pressure equal to the vaporization pressure, cavitation is observed in the entire expanding zone of the pipeline (diffuser). In turn, the absence of cavitation contributes to the establishment of an appropriate pressure throughout the entire part of the pipeline, including its narrowing part.

The cavitation area is a kind of zone through which the counteracting pressure cannot penetrate into the narrowing section of the pipe.

The pressure may drop to the vaporization pressure in the case of an increase in the rotation speeds of the pump wheels or turbines, which contributes to the occurrence of cavitation.

The negative effect of cavitation is that, as a rule, it increases resistance and energy loss. In addition, cavitation can destroy metal and cause serious damage to the pumping station and the reclamation system as a whole.

The criterion determining the cavitation properties of the impeller profiles is the cavitation number $\sigma$, determined by the following dependence: The criterion determining the cavitation properties of the impeller profiles is the cavitation number $\sigma$, determined by the following dependence:

$$
\sigma=\frac{P-P_{K}}{p V^{2} / 2},
$$

where $\mathrm{P}$ - is the pressure, $\mathrm{V}$ - is the velocity of the incoming flow.

It is known from literature sources that the liquid is supplied through the suction pipeline of centrifugal pumps due to the pressure difference in the receiving tank and in the flow at the entrance to the impeller.

As practice shows, the most common centrifugal pumps have the following arrangement schemes (Figure 3a, b, c):

Each diagram has the following designations: 1 - water source; 2 - water intake; 3 suction pipeline; 4 - pump; 5 - pressure pipeline; 6 - pressure gauge; 7 - vacuum gauge. 
HY - lower water level; BY - the upper water level; h - height from the suction socket pipeline to the second level of the pump; $Z$ - the height from the average liquid level in the suction pipe to the second level of the pump; $\mathrm{m}$ - direction of fluid movement.

Based on the above, if there are dependencies for calculating the value of the cavitation reserve, all parameters of the suction line of centrifugal pumps are calculated, but the calculated parameters are limited by many factors and, if necessary, especially with large fluctuations in the water level in the water source, it is not possible to introduce these factors into the catalog mode of operation of centrifugal pumps, which threatens to disable the pump housings and impellers up to a complete stop of the pumping station. In this case, the pump pressure drops, the supply decreases, the power consumption increases, the efficiency decreases. An increase in the cavitation reserve has almost the same effect as an increase in the water level in the water source, with the only difference that in this case the level increase is created artificially by means of a recirculation line.

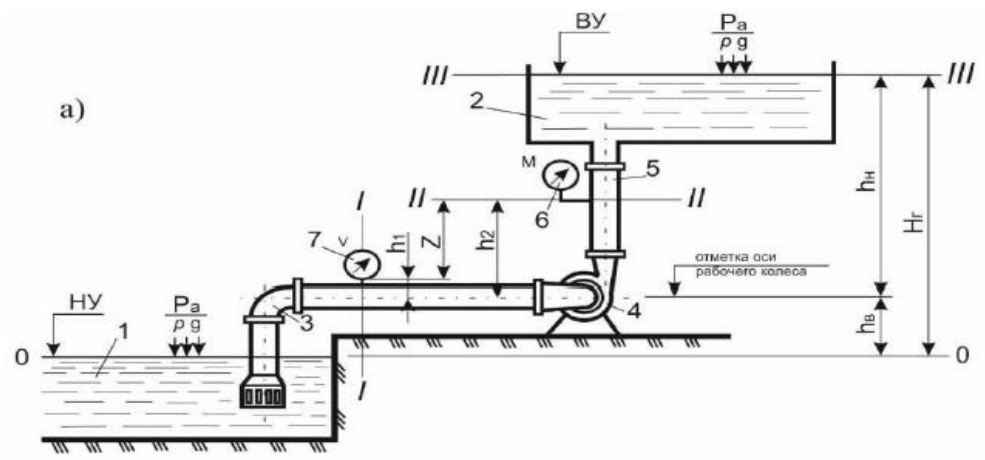

Fig. 3a. Centrifugal pump with positive suction height.

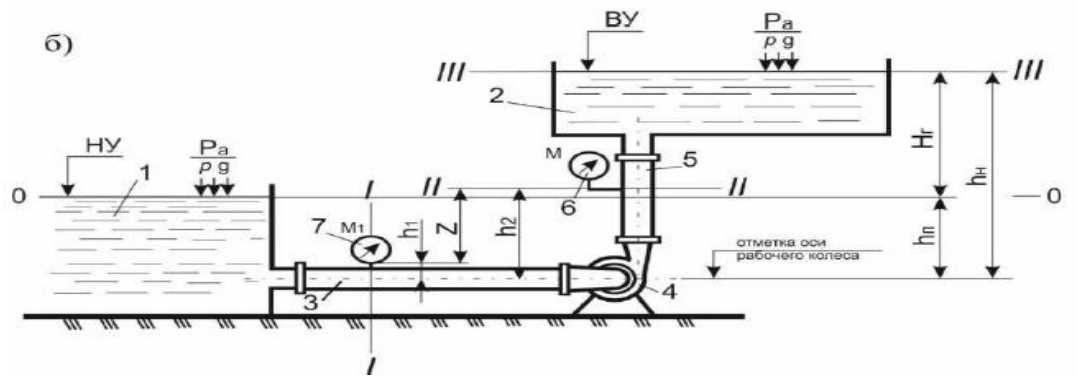

Fig. 3b. Centrifugal pump with negative suction height.

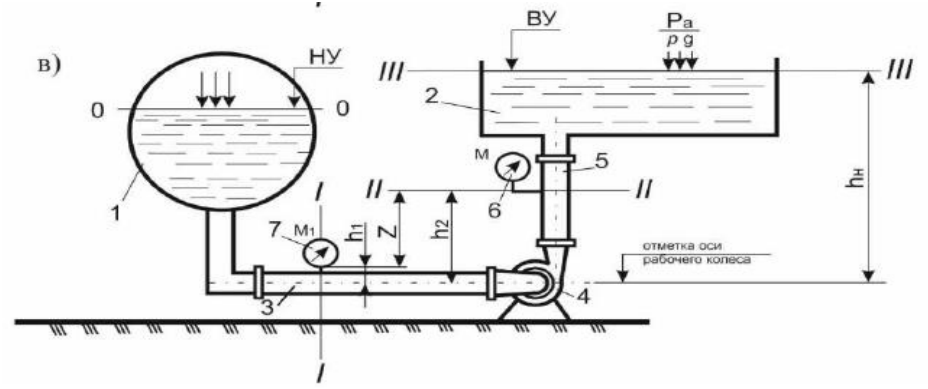

Fig. 3c. Centrifugal pump with overpressure at the inlet. 


\section{Results}

The cost component of the reconstruction of the suction pipe socket is small and is solved within the existing funds of the organization, but the profitability of the technological actions carried out will be expressed in the elimination of a large number of costs (time, material, labor costs), namely in saving hundreds of thousands of rubles, which is essential in modern economic realities. The implementation of this measure is aimed not only at saving resources, but also ensuring guaranteed reliability of the pump throughout the irrigation season in a trouble-free mode.

When studying the design documentation of the Volga irrigation system and the actual condition of the suction bell, it was found that the turn of the bell is aimed at sucking water from above the channel mirror, or the suction head itself does not have an extension (bell) on the pipeline, (Figures 4 and 5) from which physically, with minimal levels of filling the channel with water, a so-called "funnel" is formed, which picks up air into the pumping and power equipment. In practice, this circumstance adversely affects the entire operation of the pumping unit. When a "funnel" is formed, air enters the suction pipeline and, as a result, into the working chamber of the pump, which further contributes to stopping the equipment due to vacuum failure. This problem should be solved in some cases by turning the socket 180 degrees, or by installing an expanding head, so that the suction part looks down under a straight line into the bottom of the channel with the maximally expanded intake part of the suction pipeline with a self-retaining grate (Figure 6). With such a turn and the shape of the bell with a protective grid, during the supply of water supply, the "funnel" is eliminated, weeds do not enter the pumping chamber, the pumping unit operates in the planned nominal mode.

With the correct rotation of the angle of the suction socket, it becomes possible to place the beginning of the pipeline at a distance of $300 \mathrm{~mm}$ from the bottom of the channel, which will keep the water level in the channel at a minimum.

Since the diameter of the suction pipeline is larger (more voluminous) than before the reconstruction of the suction head, the intake volume of water increases and the suction speed decreases, which contributes to a smooth intake of water from the channel.

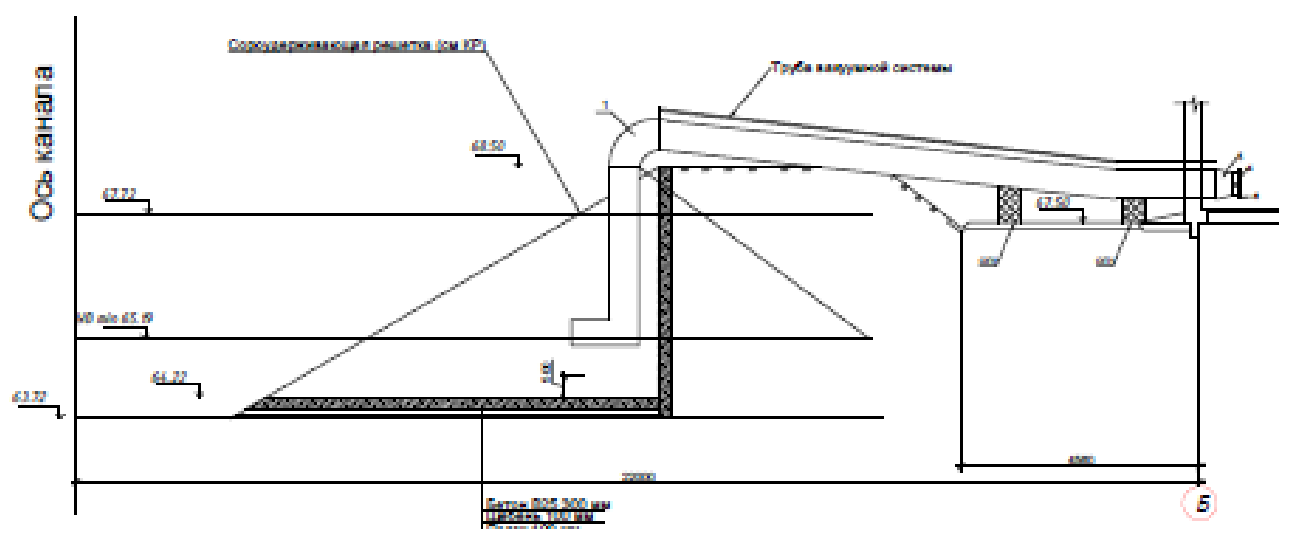

Fig. 4. View of the suction socket after reconstruction. 


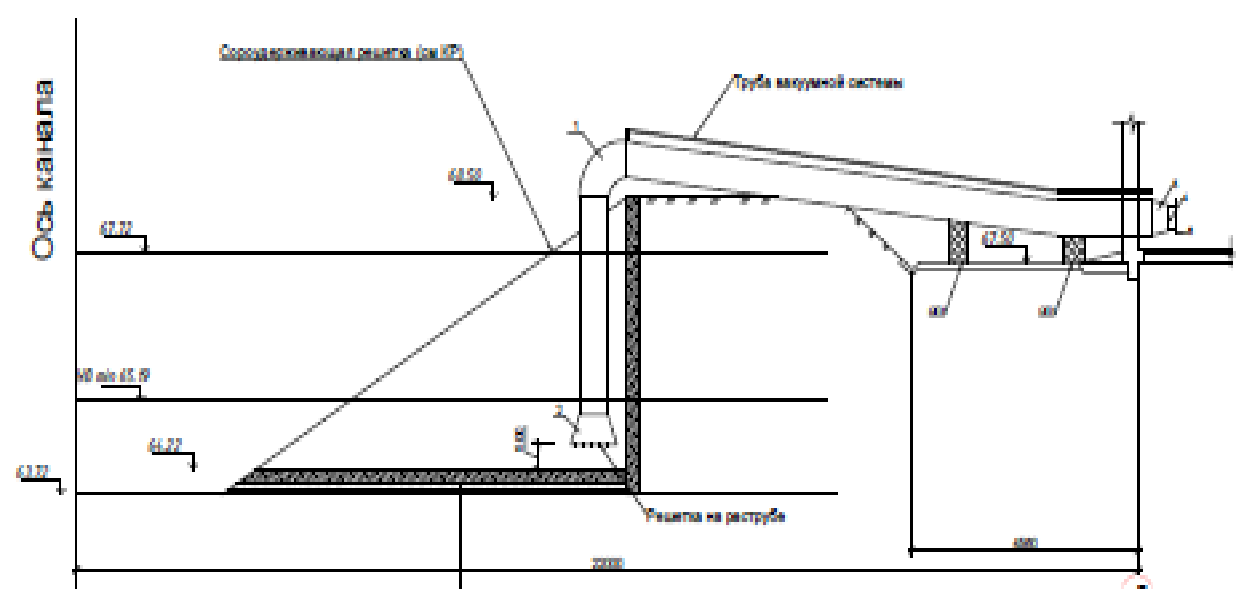

Fig. 5. View of the ante-chamber and the suction socket from above.

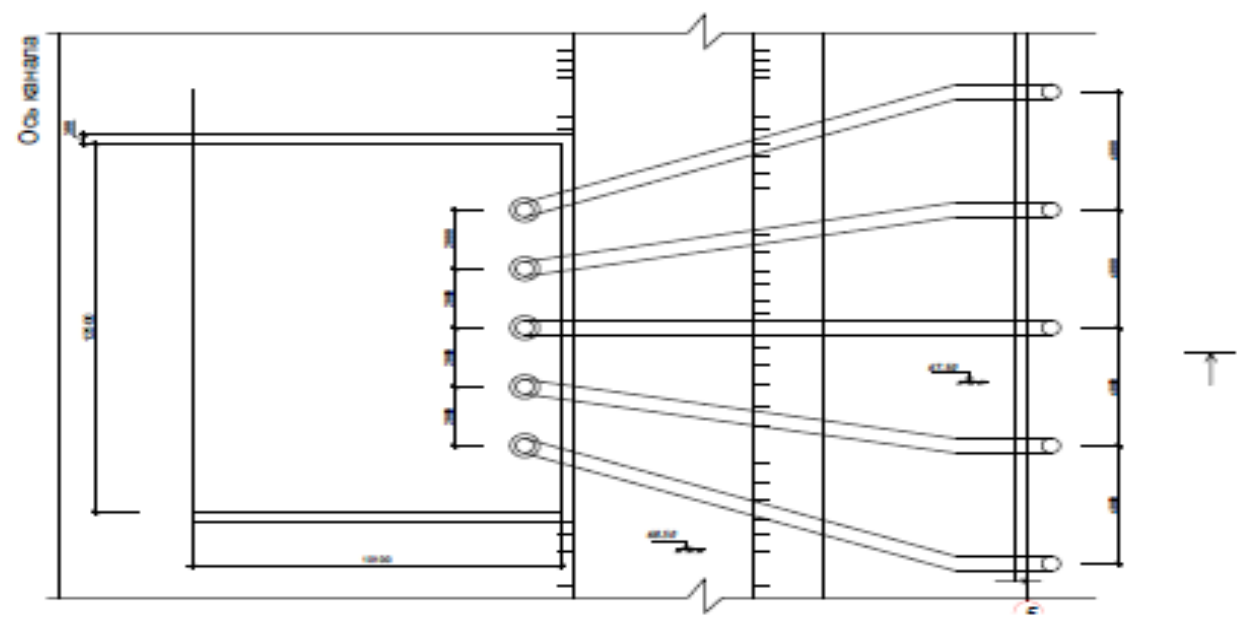

Fig. 6. Suction bell with a self-retaining grate.

So, for example, a pumping station located on the PC $15+4$ of the Volga irrigation system, with a cut installed during the construction of the canal in 1980, forces the canal to be filled according to the water level at a height of about 5 meters in the canal. During the reconstruction of the suction socket, it is enough to fill the channel for the operation of a specific pumping station at the above pickets up to 3 meters. From here it follows that with a filled water channel with a height of 5 meters, it is necessary to fill $162,000 \mathrm{~m} 3$ of water this is the operation of one unit at the head pumping station will take 9 hours and 30 minutes, while $9,300 \mathrm{~kW}$ of electricity will be consumed. with a tariff of 6 rubles per kilowatt $=55,800$ rubles, this is the amount only for filling without maintaining the required level. With the reconstructed bell, the cost of electric energy will amount to 44,640 rubles. Thus, the reconstruction of the bell saves only with a single injection of the taken part of the main channel will amount to 11,160 rubles. 


\section{Discussion}

Due to the incorrect location and design features of the suction socket, the pumping and power equipment fails, expressed in the ingress of weeds into the pump, which consequently leads to air entering the pump, funnel formation, cavitation, which generally leads to malfunctions. The problem of the need to fill the irrigation canal to the maximum level in case of incorrect location of the bell is not avoided, which directly affects the high costs of electricity, and this is currently not allowed in economic terms. Therefore, ignoring the technological features and the location of the suction bell in the irrigation channel, there will be costs for replacing the impeller of pumping equipment, the cost of one varies from 50,000 to 80,000 t.r. The correct location of the bell allows you to reduce the volume of filling in the main channel of the Volga irrigation system by almost a quarter. So, in order to fill part of the main channel from pumping station No. 1 to pumping station No. 5 to the working level, 650 thousand cubic meters of water are needed if the sockets of the pumping pumping stations are incorrectly located. With proper design of the bell, it is enough to keep the water in the channel at the level of 416 thousand cubic meters. And this, with an average cost of electric energy of 6 rubles per $1 \mathrm{~kW}$ and a pump capacity equal to 1700 cubic meters per hour with an electric motor power of $1000 \mathrm{~kW}$, savings on average will amount to 78,000 rubles, with a one-time operation of a cascade of pumping stations.

Thus, the constructive change of the suction socket has a positive effect and guarantees the operation of the entire pumping station located on the main channel. The calculations show the advantages of an economic and technological nature. An assessment of the financial efficiency of the reconstruction of the pipes on the Volga irrigation system allows us to conclude that the project is cost-effective and is recommended for implementation. Reconstruction of the suction head eliminates the ingress of weeds into the equipment, eliminates the need to fill the main channel to the maximum level, the "funnel" is eliminated. And on the example of the operation of the vacuum system, before starting the main units, there is confirmation that the water intake from the channel is carried out faster and technologically correct.

\section{Conclusion}

Reconstruction and modernization of the suction pipe socket at the pumping stations of the Volga irrigation system will lead to operational reliability of pumping equipment and increase its productivity, by avoiding cavitation and possible clogging of the pumping unit, the cost of paying for electric energy for maximum filling of the channel with water will be reduced, since the channel will be filled to the required minimum level.

\section{References}

[1] F. K. Abdrazakov, A. A. Rukavishnikov, O. V. Miheeva, D. V. Logashov, S. I. Churkina, M. A. Yarmashevich, 2020, Construction and Repair of Irrigation Canals Based on Converged Technologies International Scientific Conference: "Constructions Mechanics, Hydraulics and Water Resources Engineering", 6

[2] F. K. Abdrazakov, D. V. Logashov, 2020, Analysis of the work of komsomolskaya pumping stationsand volga irrigation systems, disadvantages and ways to improve them Agrarian scientific journal,

[3] F. K. Abdrazakov, D. V. Logashov, A. A. Rukavishnikov, 2021, Reconstruction of the suction pipeline with a change in the bell of 
electrified pumping stations of the volga irrigation system Agrarian scientific journal, 1

[4]F. K. Abdrazakov, D. V. Logashov, A. A. Glushchenko, 2021, The bell of the suction pipeline of reclamation pumping stations, Modern problems and prospects for the development of construction, heat and gas supply and energy supply: Materials of the XI National Conference with international participation, Saratov, 6

[5] N. V. Rejunov, D. V. Kolzhanov, S. A. Tarasyants, 2010, Cavitation as a physical phenomenon in dredging plants Resource-saving environmentally sustainable technologies in agricultural production: Materials of the International Scientific and Practical Conference (Shumakov Readings together with a meeting of the RASC section), Novocherkassk, 10

[6] O. I. Rakhnyanskaya, Yu. V. Bandyukov, K. A. Degtyareva [et al.], 2015, Calculation of operational parameters of pumping equipment and pipeline network of water supply and reclamation pumping stations Polythematic network electronic scientific journal of Kuban State Agrarian University, 110

[7] S. A. Tarasyants, A.V. Yudakov, 1997, Economic issues of pumping station operation Personnel and scientific and technical progress in land reclamation: Materials of the All-Russian Scientific and Technical Conference, Novocherkassk, 1

[8] O. I. Rakhnyanskaya, S. A. Tarasyants, Yu. S. Urzhumova, 2017, Criterion of cavitation-free operation of jet devices, Land reclamation and water management. Ways to improve the efficiency and environmental safety of land reclamation in the South of Russia: materials of the All-Russian Scientific and Practical Conference, Novocherkassk, 1

[9] V. Bandyukov, P. V. Pashkov, S. S. Anan'ev, A. S. Tarasians, 2017, Calculation of operational parameters of pumping equipment and pipeline network of water supply and reclamation pumping stations, Agrarian scientific journal, 5

[10]] S. A. Tarsians, P. V. Pashkov, V. N. Shiryaev, N. A. Maidannikov, 2018, Cavitation and ways to increase the cavitation reserve of axial pumps when water levels drop in water sources, Vestnik of Ryazan state agrotechnological University. After P. A. Kostychev, 37

[11] Bykowski Jerzy, Napierała Michał, Przybyła Czesław, 2015, Energy efficiency assessment of retrofits' land reclamation pumping stations, Energy efficiency assessment of retrofits' land reclamation pumping stations, 17

[12] Mariana Mirela Stoican, Nikolae Baran, 2021, Designing and dimensioning of a new type of pump that can be used in the field of land reclamation, E3S Web of Conferences, 286 